\title{
Value of a value culture survey for improving healthcare quality
}

\author{
Sara J Singer
}

Medicine, Stanford University School of Medicine, Stanford, California, USA

\section{Correspondence to} Dr Sara I Singer, Medicine, Stanford University School of Medicine, Stanford, CA 94305, USA; ssinger@stanford.edu

Accepted 1 October 2021

\section{Linked}

- http://dx.doi.org/10.1136/ bmjgs-2020-012407

\section{Check for updates}

(C) Author(s) (or their employer(s)) 2021. No commercial re-use. See rights and permissions. Published by BMJ.

To cite: Singer SJ. BMJ Qual Saf Epub ahead of print: [please include Day Month Year]. doi:10.1136/ bmjqs-2021-014048
The article by Sorra and colleagues in this issue of BMJ Quality and Safety ${ }^{1}$ reflects a subtle but important shift in national efforts to enhance quality in healthcare. Since 2000 and the publication of To Err is Human, ${ }^{2}$ there has been widespread recognition of the need to address patient safety issues at a systems level. This and subsequent discourse directed attention to organisational culture as a key lever for ensuring safety and quality. The follow-on Crossing the Quality Chasm report acknowledged the multidimensionality of the cultural challenge by recommending redesign of the American healthcare system including six aims for improvement-safety, effectiveness, patientcenteredness, timeliness, efficiency and equity. ${ }^{3}$ However, safety has received the lion share of attention over the last two decades, perhaps due to Hippocrates' admonition to 'first, do no harm'. Efficiency has been particularly neglected. Despite painfully high, and relentlessly increasing, healthcare spending as a percent of US gross domestic product ${ }^{4}$ and embarrassing comparisons of outcomes for our spending, ${ }^{5}$ efforts in the USA to address escalating costs of healthcare have been relatively recent ${ }^{67}$ and have not sought to address organisational culture. Even in countries that achieve higher value, that is, patient experience and outcomes over cost, greater efficiency must be an enduring goal.

In this context, the article by Sorra and colleagues is remarkable. In a project supported by the US Agency for Healthcare Research and Quality, they offer a set of new survey items to assess the culture of value and efficiency in hospitals and medical offices. ${ }^{1}$ More importantly, they offer a vision, derived with extensive input from academic experts and clinical professionals, for understanding the role of value and efficiency in promoting quality that policymakers, health system leaders and frontline healthcare workers can embrace. Since the authors did not do so explicitly, below I offer a conceptual model implied in this research (figure 1). The model suggests that value and efficiency culture interacts with quality and safety culture and is thus a key contributor and enabler of healthcare quality. In other words, cost and quality go hand in hand in a $1+1=3$ type relationship. Streamlining workflows and doing things right the first time enhances quality by improving efficiency. Quality/safety culture and value/efficiency culture have potential for synergy such that their combined impact on outcomes is more than the two independent effects. The more staff gain experiences with activities to improve efficiency, the higher and stronger, that is, more widely shared, the culture of value and efficiency. Value/efficiency culture also increases the likelihood that organisations and managers will ensure staff have further experiences with activities to improve efficiency. This conceptual model is consistent with theoretical frameworks that describe cultural evolution as a process of enabling, enacting and elaborating the desired culture. ${ }^{89}$

How health systems administer and use the new value/efficiency item set is critical. As the conceptual model makes clear, value/efficiency culture should be considered jointly with safety culture, not as a replacement, to understand the outcomes it will produce in patient care. Surveys are teaching and expectation setting tools as much as evaluation tools; thus, including both dimensions of quality signals their equal importance and synergistic potential to the organisation. Additionally, differences in the pattern of results would suggest different approaches for addressing them. For example, where a site exhibits low efficiency culture but high safety culture, an organisation might benefit from training, 


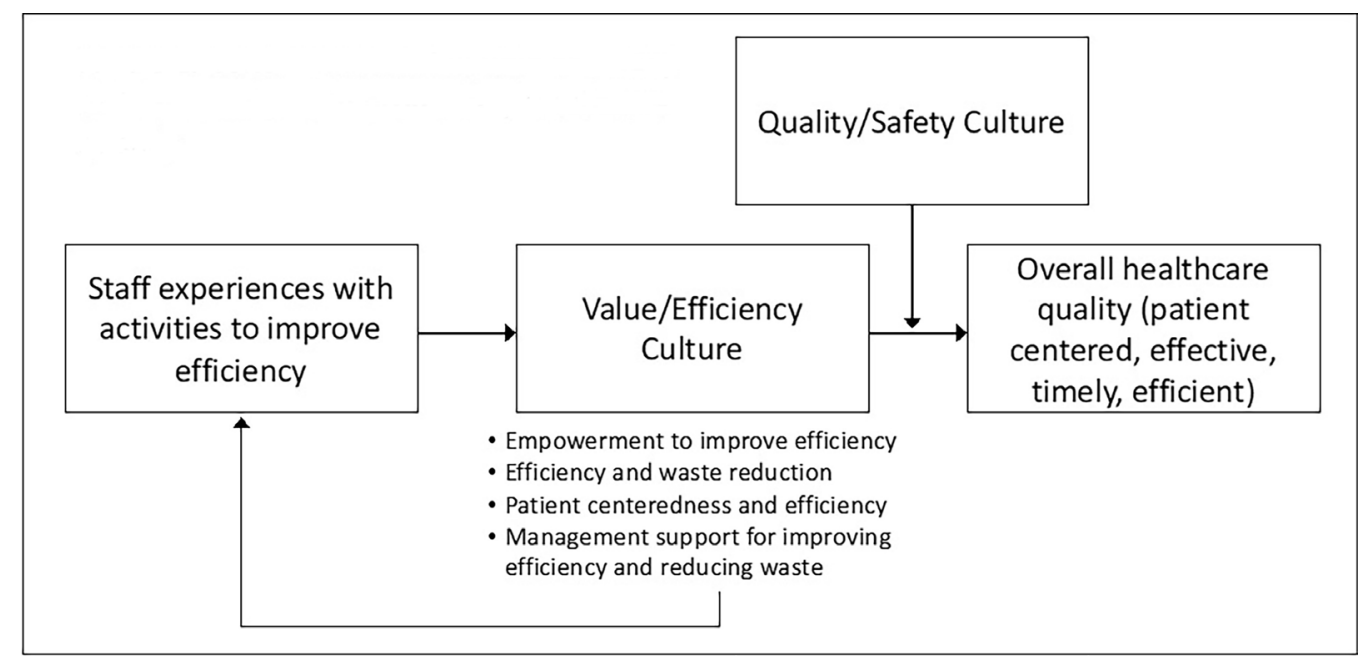

Figure 1 Conceptual model: role of value/ efficiency culture in promoting healthcare quality.

incentives, or programmes that highlight models where value and efficiency enhance safety and quality. In contrast, where efficiency and safety culture are both low, the site may need more basic infrastructure-like personnel and capacity for data collection and analysis-to enable any sort of improvement. Likewise, efforts to use value/efficiency culture results to spur 'lean thinking' and other approaches to improve value culture must emphasise the utility of efficiency for improving quality to prevent a 'cost-cutting as an end in itself' mentality to pervade.

Findings from the pilot test of this culture of value and efficiency survey suggest additional, actionable strategies for using survey data from the new items. In this context, it is worth restating the authors' conclusion that 'It is clear from these results that much more needs to be done within healthcare organisations to ensure that activities focused on value and efficiency are supported and conducted'. The first actionable strategy is related to the item receiving the lowest score for both hospitals and medical offices: 'We invite patients to serve on advisory panels or committees to help us improve the patient care experience.' While recommended for patient-centred medical homes ${ }^{10}$ and required as part of research endeavours supported by the Patient-Centred Outcomes Research Institute (PCORI) ${ }^{11}$ healthcare organisations often baulk at involving patients in efforts to improve patient care ${ }^{12}$ despite examples of the benefits of patient engagement. ${ }^{13}$ A second strategy is that particular attention should be given to management support for improving efficiency and reducing waste in hospitals and in medical offices, the dimensions with the lowest scores. The low scores for hospitals and medical groups on measures of experience with activities to improve efficiency suggest opportunities for managers to show support for improving efficiency and reducing waste through encouraging more exposure to these activities.
The second actionable strategy-encouraging management support and efforts to increase experiences with efficiency and waste reduction activitiesrequires alignment of incentives for managers and staff. Payers must continue building on value-based payment reforms, including the Medicare Access and CHIP Reauthorization Act of 2015 (MACRA), and primary-care focused initiatives like Comprehensive Primary Care Plus (CPC+), ${ }^{14}$ the Global and Professional Direct Contracting Model ${ }^{15}$ and the Primary Care First Model $^{16}$ to ensure that healthcare organisations have more reasons to improve value than to increase services. Beyond financial incentives, acknowledgement and recognition for managers and staff that support value-enhancing initiatives and for healthcare organisations that achieve higher value would motivate attention to improving efficiency.

Another noteworthy finding was that clinical staff had more positive value and efficiency culture perceptions than did non-clinical staff, and that among non-clinical staff, managers were more positive than non-managers. One explanation for clinicians' positive perceptions may be that they benefit more from efforts to improve efficiency because they are closer to the patients who benefit. Lower perceptions among non-clinical staff, however, suggest the importance of raising awareness among non-clinicians, particularly among those with financial and purchasing responsibility who many have authority to impact efficiency. That managers' perceptions are more positive is not surprising given similar findings about safety culture. ${ }^{17}$ However, such findings also suggest that managers may underestimate leadership needed to enable a culture of value and efficiency. Therefore, within a strategy to garner sufficient management support, efforts to ensure managers understand the perceptions and concerns of frontline workers will be important. 
The authors found significant and sizeable intraclass correlations, confirming that site membership impacts the way individuals responded to the survey. Also, substantial SDs were found particularly among medical groups. These findings confirm that value and efficiency culture is an attribute of organisations and that it varies meaningfully among organisations. As with safety culture, comparative studies would therefore offer opportunities for identifying and learning from high performing sites. Meaningful variation is also likely across units within organisations. The authors recommended learning from healthcare systems that are well known for their focus on culture change to improve high-value healthcare. However, emulating organisational improvement programmes has proven difficult given differences in organisational characteristics and contextual factors, so local comparisons can prove especially valuable. ${ }^{18}$ Comparing higher to lower scoring units within institutions in order to identify opportunities for learning among lower performers, as is often done with safety culture, will likely yield similar benefits in the context of value.

Efforts to measure and improve value and efficiency culture would benefit from additional research. Although reasonable given the authors' constraints and goals, by choosing not to administer the new value/efficiency culture items together with the original survey and by not conducting an exploratory factor analysis, this also means they missed learning opportunities. Future research should fill these gaps and use survey-derived empirical data to explore how value/efficiency culture is related to quality/safety culture from the perspective of frontline workers. Particularly considering high correlations between some factors (as high as 0.85 in the hospital sample), an exploratory approach to determining an underlying simple structure in the data could yield new insights about how workers think about relationships among value/efficiency concepts. ${ }^{19}$ Investigators could administer the Survey on Patient Safety Culture together with the new value and efficiency item set. If the sample were sufficiently large, they could use responses to both quality/safety and value/efficiency items and perform exploratory factor analysis. Doing so could shed additional light on relationships among concepts. For example, a strong relationship between concepts may suggest that there are mechanisms that foster both or that one may facilitates achievement of another. Such an understanding could be helpful in designing additional recommendations for action. The survey also requires additional validation, which could be achieved by comparing survey results to other measures of value and efficiency, such as those derived through time-based activity-based costing. ${ }^{20}$

Meanwhile, the value/efficiency item set as developed by Sorra et al offers hospitals and medical groups a valuable opportunity as an excellent starting point to measure and increase their understanding of an important aspect of organisational culture and key contributor to healthcare quality.

Twitter Sara J Singer@sarajsinger

Funding The authors have not declared a specific grant for this research from any funding agency in the public, commercial or not-for-profit sectors.

Competing interests None declared.

Patient consent for publication Not applicable.

Provenance and peer review Commissioned; internally peer reviewed.

ORCID iD

Sara J Singer http://orcid.org/0000-0002-3374-1177

\section{REFERENCES}

1 Sorra J, Zebrak K, Yount N, et al. Development and pilot testing of survey items to assess the culture of value and efficiency in hospitals and medical offices. BMJ Qual Saf 2021:bmjqs-2020-012407.

2 Institute of Medicine. Committee on Quality Health Care in America. In: To err is human: building a safer health system. Washington, DC: The National Academies Press, 2000.

3 Institute of Medicine. Committee on Quality Health Care in America. In: Crossing the quality chasm: a new health system for the 21st century. Washington, DC: National Academy Press, 2001.

4 Martin AB, Hartman M, Lassman D, et al. National health care spending in 2019: steady growth for the fourth consecutive year. Health Aff 2021;40:14-24.

5 Schneider EC, Shah A, Doty MM. Reflecting poorly. health care in the U.S. compared to other high-income countries. New York: NY: Commonwealth fund. fund report, 2021. Available: https://www.commonwealthfund.org/publications/ fund-reports/2021/aug/mirror-mirror-2021-reflecting-poorly

6 Centers for Medicare and Medicaid Services (CMS). MACRA 2019: what's MACRA?Available: https://www.cms.gov/ Medicare/Quality-Initiatives-Patient-Assessment-Instruments/ Value- Based-Programs/MACRA-MIPS-and-APMs/MACRAMIPS-and-APMs

7 Centers for Medicare and Medicaid Services (CMS). Quality payment program (QPP). APMs overview, 2019. Available: https://qpp.cms.gov/apms/overview

8 Vogus TJ, Sutcliffe KM, Weick KE. Doing no harm: enabling, enacting, and elaborating a culture of safety in health care. Acad Manag Perspect 2010;24:60-77.

9 Singer SJ, Vogus TJ. Reducing Hospital errors: interventions that build safety culture. Annu Rev Public Health 2013;34:373-96.

10 National Committee for Quality Assurance Patient-Centered Medical Home Program. PCMH 2011-PCMH 2014 Crosswalk, 2021. Available: http://bit.ly/1xouu23

11 House Office of the Legislative Counsel. Compilation of patient protection and Affordable care act: patient-centered outcomes research and the authorization of the patientcentered outcomes research Institute (PCORI). Sec. 6301. 111th Cong., 2nd Sess. (enacted March 23, 2010; amended through may 1, 2010), 2021. Available: https://www.pcori.org/ sites/default/files/PCORI-Authorizing-Legislation.pdf

12 Han E, Hudson Scholle S, Morton S, et al. Survey shows that fewer than a third of patient-centered medical home 


\section{Editorial}

practices engage patients in quality improvement. Health Aff 2013;32:368-75.

13 Forsythe LP, Carman KL, Szydlowski V, et al. Patient engagement in research: early findings from the patientcentered outcomes research Institute. Health Aff 2019;38:359-67.

14 Centers for Medicare and Medicaid Services. Comprehensive primary care plus, 2021. Available: https://innovation.cms.gov/ innovation-models/comprehensive-primary-care-plus

15 Centers for Medicare and Medicaid Services. Global and professional direct contracting (GPDC), 2021. Available: https://innovation.cms.gov/innovation-models/gpdc-model

16 Centers for Medicare and Medicaid Services. Primary care first model options, 2021. Available: https://innovation.cms.gov/ innovation-models/primary-care-first-model-options
17 Singer SJ, Falwell A, Gaba DM, et al. Patient safety climate in US hospitals: variation by management level. Med Care 2008;46:1149-56.

18 Westphal JD, Gulati R, Shortell SM. Customization or conformity? an institutional and network perspective on the content and consequences of TQM adoption. Adm Sci Q 1997;42:366.

19 Singer S, Meterko M, Baker L, et al. Workforce perceptions of hospital safety culture: development and validation of the patient safety climate in healthcare organizations survey. Health Serv Res 2007;42:1999-2021.

20 Xue J, Hinkle J, Reeves M-G, et al. A cost comparison of cataract surgeries in three countries - United States, India, and Nepal. NEJM Catalyst 2021;2. 